\title{
TNFR/TNF-a signaling pathway regulates apoptosis of alveolar macrophages in coal workers' pneumoconiosis
}

\author{
Qing-Zeng Qian ${ }^{1}$, Xiang-Ke Cao ${ }^{2}$, Hai-Yan Liu ${ }^{1}$, Guo-Ying Zheng ${ }^{1}$, Qing-Qiang Qian ${ }^{3}$ \\ and Fu-Hai Shen ${ }^{1}$ \\ ${ }^{1}$ School of Public Health, North China University of Science and Technology, Tangshan 063000, P.R. China \\ ${ }^{2}$ College of Life Sciences, North China University of Science and Technology, Tangshan 063000, P.R. China \\ ${ }^{3}$ Department of Neurology, Tangshan Gongren Hospital Affiliated to North China University of Science and Technology, Tangshan \\ 063000, P.R. China
}

Correspondence to: Fu-Hai Shen, email: fuhai_sh@163.com

Keywords: coal mixture workers, coal workers' pneumoconiosis, cumulative dust exposure, alveolar macrophages, apoptosis

Received: July 27, $2016 \quad$ Accepted: May 23, $2017 \quad$ Published: July 01, 2017

Copyright: Qian et al. This is an open-access article distributed under the terms of the Creative Commons Attribution License 3.0 (CC BY 3.0), which permits unrestricted use, distribution, and reproduction in any medium, provided the original author and source are credited.

\section{ABSTRACT}

We explored the role of TNFR/TNF-a signalingin apoptosis among alveolar macrophages (AM) and its relevance to the development of coal workers' pneumoconiosis (CWP). Purified alveolar macrophages (AMs) were prepared from bronchoalveolar lavage fluid harvested from 366 CWP patients and 120 healthy subjects enrolled inthe study. The purified AMs were then divided into control, SOD, anti-TNFR, TNFR and NFkB inhibitor groups and analyzed for apoptosis usingflow cytometry (sub-diploid peak) and western blotting (Bcl-2, Caspase-3 and Caspase-8 expression). We found thatAM apoptosis washigher amongCWP patients than thehealthycontrols. Expression ofBcl-2, Caspase-3 and Caspase-8 was higher inAMs from CWP patientsthan in those from the controlsand correlated with increased AM apoptosis. Univariate and multivariate analyses suggested that CWP grade, initial exposure time, exposure time inyears, and CWP onset agewereall associated with altered levels of $\mathrm{Bcl}-2$, Caspase-3 and Caspase-8. Inhibition of TNFR/TNF-a signaling usinganti-TNFR antibody, SOD or NFkB inhibitionreduced AM apoptosisand decreased Bcl-2, Caspase-3 and Caspase-8 expression. These data suggestinhibition of a TNFR/TNF-a signaling pathway is a potentiallyeffective means ofalleviating CWP by inhibiting AM apoptosis.

\section{INTRODUCTION}

Although there is increased emphasis on physical health and regularhealth examinations at work places, occupational disease rates have increased significantlywithrapid development of China's coal industry [1-3]. Long-term exposure of mining workers to coal dustcontributes to increased risk of chronic occupational lung diseases and irreversible lung damage $[4,5,6]$. Coal workers' pneumoconiosis (CWP) is one of the most common lung diseasesassociated with different degrees of pulmonary function abnormalities in coal mining workers [7]. It is one of the most serious occupational diseases in Chinathatresults inlungfibrosis due to long-term inhalation of coal dust $[8,9]$. Previous studies have associatedlong-term exposure to coal mine dust with CWP mortality [10]. Stringent enforcement of occupational exposure limits for coal mine dust has resulted in declined prevalence of CWP among underground coal miners [11]. However, miners still working incontemporary conditionscontinue to develop lung diseases, therebyimplyingthat further restrictions and regulations in occupational dust exposure are necessary [12].

Apoptosis refers toa genetically controlled program of cell death that is involved in elimination of old or unhealthy cells that could be detrimental to organismal health. In recent years, investigation of CWP pathogenesis has revealed thatapoptosis ofalveolar macrophages (AM) is involved in development of pneumonia and pulmonary fibrosis [13]. The three major signal transduction pathwaysthat regulate AM apoptosis includethe mitochondrial pathway, the 
endoplasmic reticulum pathway, and the membraneassociated cell death receptor pathway [14-17]. Thecell death receptorsbelonging to the members of the TNFR super-family initiate apoptosis upon binding to their ligands and operate mainly through three basic signal transduction pathwaysnamely, Fas/Fas ligand (FasL), TNFR/TNF- $\alpha$, and TRAILR/TRAIL $[18,19,20]$. These pathways ultimately modulate critical players of apoptosis includinginitiator and executioner caspases, P53, Bcl-2 and other apoptotic regulatory proteins [21]. Therefore, blocking the death receptor mediated apoptosis of AM is probably an effective measure to prevent or cure CWP [22]. Therefore, in this study, weexplored the role of TNFR/TNF- $\alpha$ signaling pathway in AM apoptosis and association to CWP. We also investigated if inhibition of TNFR/TNF- $\alpha$ signalingcould provide a therapeutic basis for the early prevention and treatment of CWP.

\section{RESULTS}

\section{Baseline characteristics of CWP patients}

In the exposed group, the mean age of the 366 coal mine workers was $47.8 \pm 9.2$ years (range: 24 to $65 \mathrm{y}$ ) and the mean body weight of included subjects was $57.7 \pm$ $10.3 \mathrm{~kg}$ (range:42 86 kg). In the control group, the mean age of the 120 coal mine workers was $48.2 \pm 8.4$ years (range:28 to 68 years) and the mean body weight of control subjects was $56.8 \pm 10.5 \mathrm{~kg}$ (range:43 85 kg). As shown, there were no significant differences between the exposed and the control group with regard to mean age and body weight (both $P>0.05$ ). The other baseline characteristics includingsmoking status, initial working time, occupational history, current occupation, retirement period and others were all similar between the exposed and the control groups (all $P>0.05$; Table 1).

\section{Apoptosis status of AM in CWP patients}

Figure 1 shows therepresentative images of control and CWP patient alveolar macrophages (AM). The mature normal AM from control subjects showed increased cell volume, integral cell membrane, round or oval shaped cell-centric nucleusand were free of intracellular dust particles. The apoptotic AM cells from CWP patients showed marginalizedchromatinandfragmented nucleus with massive apoptotic bodies typical ofapoptosis.

\section{Comparison of $\mathrm{AM}$ apoptosis among different subgroups of CWP patients}

The apoptotic AM cells were analyzed by flow cytometry and the sub-diploid peak representing the AM cells undergoing apoptosis is shown in Figure 2. Our analysis showed that AM cells from CWP stage I and stage II patient groups showed significantly higher apoptosisthan those from normal controls (both $P<0.05$ ). Further, apoptosis in AM cells from CWP stage I patients was significantlyenhanced compared to thosefromCWP stage IIpatients $(P<0.05)$. Table 2 shows the apoptotic index ofsubjects in the exposed group stratified by age, smoking, initial exposure time, exposureyears, and CWP onset age. Except for the subgroup representing different exposure years $(P<0.05)$, there was no significantdifferencein apoptosis betweenothersubgroups (all $P>0.05$ ).

\section{Analysis of the expression of key apoptotic regulatory proteins in AM from CWP patients}

As shown in Table 3, we observed thatthe expression of key apoptotic regulatory proteins, Bcl-2, Caspase- 3 and Caspase- 8 was significantly enhancedin the exposed group compared to those in the control group (all $P<0.05$ ). Besides, there were positive correlation between elevated expression of Bcl-2, Caspase- 3 and Caspase- 8 and enhanced AM apoptosis (all $P<0.05$ ).

Furthermore, we conducted stratified analysesinvestigating the association between the expression levels of Bcl-2, Caspase-3 and Caspase- 8 with factors likeage, smoking, CWP stages, initial exposure time, exposureyears, and CWP onset age (Table 4). Our data showed significant association between the expression levels of Bcl-2, Caspase- 3 and Caspase- 8 anddifferent subgroups based onage, smoking, initial exposure time, exposureyears, and CWP onset age (all $P<0.05)$. In addition, multivariate analysis indicated that altered expression levels ofBcl-2, Caspase-3 and Caspase8significantly correlated with CWP stages. Besides, initial exposure time, exposureyears, and CWP onset agecorrelated withthe expression levels of Caspase- 3 . Also, Caspase-8 expression levels were associated withexposureyears, whereas expression levels of Bcl-2 were influenced by CWP onset age (all $P<0.05$ ).

\section{Regulatory role of TNFR/TNF- $\alpha$ signal pathway in $\mathrm{AM}$ apoptosis from CWP patients}

Next, we investigated the role of TNFR/TNFasignaling pathway in regulating AM apoptosis. We observed that the apoptotic index of AM in the SOD group $(14.23 \pm 2.01)$ was significantly lower than that in the control group $(23.47 \pm 2.68)$ and the TNFR group $(18.33 \pm 1.80)$. Furthermore, the apoptotic index of AM in the anti-TNFR group $(14.00 \pm 1.45)$ and NF-kB inhibitor group (13.52 \pm 1.77$)$ were also significantly reduced when compared to the TNFR group (all $P<0.05$ ).

Consequently, the expression levelsof $\mathrm{Bcl}-2$, Caspase- 3 and Caspase- 8 were significantly decreased when TNFR/TNF- $\alpha$ signaling pathwaywas blocked SOD and was least compared to all other 4 groups (all $P<0.05)$. In addition, blocking theTNFR/TNF- $\alpha$ signal 
Table 1: Comparisons in smoking rate, pulmonary function and pulmonary function indexes between the case group and the control group

\begin{tabular}{ccccc}
\hline Group & Exposed group $(\boldsymbol{n}=\mathbf{3 6 6})$ & Control group $(\boldsymbol{n}=\mathbf{1 2 0})$ & $\boldsymbol{\chi}^{2} / \boldsymbol{t}$ & $\boldsymbol{P}$ \\
\hline Age (year) & $47.80 \pm 9.20(24 \sim 65)$ & $48.20 \pm 8.40(28 \sim 68)$ & 0.422 & 0.673 \\
Weight $(\mathrm{kg})$ & $57.70 \pm 10.30(42 \sim 86)$ & $56.80 \pm 10.50(43 \sim 85)$ & 0.409 & 0.827 \\
Smoking distribution & & & & \\
Non-smoking & $165(45.08 \%)$ & $57(47,50 \%)$ & 0.462 & 0.645 \\
Smoking & $201(54.92 \%)$ & $63(52.50 \%)$ & & \\
Initial working time & $21.10 \pm 4.16$ & $22.00 \pm 5.50$ & 1.890 & 0.059 \\
Work years & $23.50 \pm 5.85$ & $24.34 \pm 6.78$ & 1.311 & 0.191 \\
Retirement period & $3.83 \pm 1.11$ & $4.05 \pm 1.06$ & 1.905 & 0.057 \\
\hline
\end{tabular}

Note: Initial working time, the starting age of workers exposed to dust; work years, the length of the time employed; retirement period, the duration after stopping dust exposure of workers exposed to dust.

pathwaywithanti-TNFR antibody or NFkB inhibitor significantly reduced expression levels of Bcl-2, Caspase- 3 and Caspase- 8 compared with the control group and the TNFR group (all $P<0.05$ ). Thedata areshown in Figure 3 and Table 5 .

\section{DISCUSSION}

CWP is a result of long-term inhalation of coal mine and silica dust thatresults in impaired pulmonary function and lung diseases, therebyrepresenting a relevant occupational hazard for coal miners [8]. Despite dust control and reduction technology being utilized in the recent decades, the morbidity of CWPhas showedincreased incidence [23]. Sincethe mechanistic details of CWP pathogenesis are not clear, the prevention and treatment of CWP has been a challenge. Hence, it is very important to explore mechanismsthat promote CWP in order to obtain greater understanding of this disease and identify effective treatment methods. In vivo and in vitro studies have shown

\section{A}

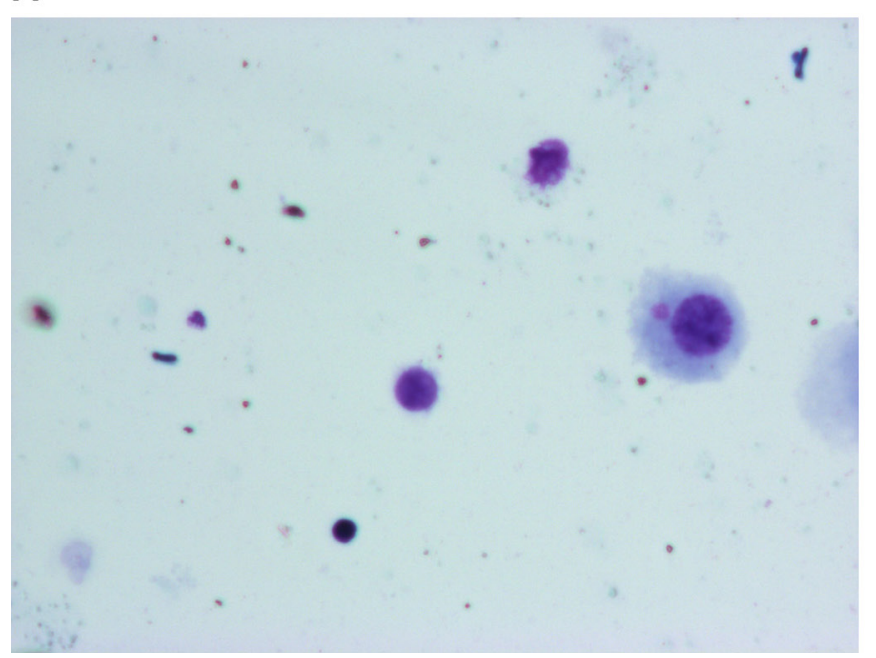

that AM plays an important role in CWP [24, 25]. Thedust particles that enter the alveoli are phagocytosed by the AM cells that results in their activation and caspase-dependent apoptosis. In the present study, we investigated the role of TNFR/TNF-asignaling pathway in the pathogenesis of CWP and explored if it represented a relevant strategy to inhibit CWP.

Apoptosisis a systematic program of cell deathwhich is initiated by specific signaling pathways in response to either external or intracellular stimuli and executed by sequential activation of specific apoptosis regulatory proteins like caspases [26, 27]. Cellular apoptosis is animportant physiological mechanism in multicellular organisms, which is critical for maintaining body's normal development and homeostasis and is involved in organ development, tissue repair and immune regulation $[28,29]$. In the present study, we observed that alveolar macrophages showed typical characteristics of apoptosis likechromatin marginalization and nuclear fragmentation into massive intracellular apoptotic bodies [30]. Our study

\section{B}

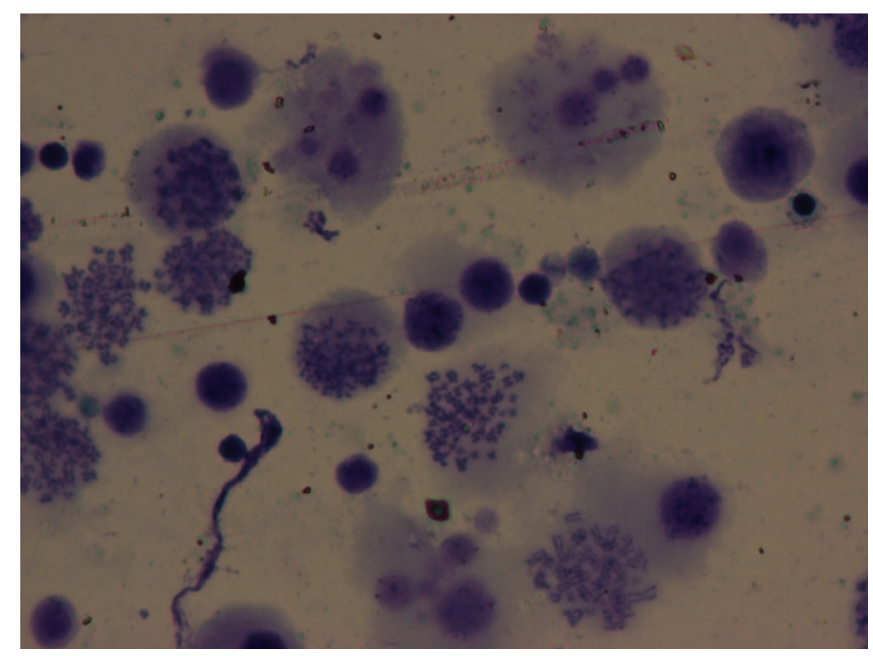

Figure 1: Representative H\&E stained photographs of alveolar macrophages undergoing apoptosis as observed underlight microscope (1000×). (A) Alveolar macrophages from normal controls; (B) Apoptotic alveolar macrophages from CWP patients. 
Table 2: Comparisons of alveolar macrophages apoptosis among different subgroups based on age, smoking, initial working time, occupational time, and working age for occurrence in the exposed group

\begin{tabular}{|c|c|c|c|c|}
\hline Group & $\mathbf{N}$ & Apoptotic index & $\chi^{2} / t$ or $F$ & $\boldsymbol{P}$ \\
\hline \multicolumn{5}{|l|}{ Age } \\
\hline$<40$ & 156 & $27.22 \pm 5.47$ & 0.597 & 0.551 \\
\hline$\geq 40$ & 210 & $26.88 \pm 5.25$ & & \\
\hline \multicolumn{5}{|c|}{ Smoking (duration time, years) } \\
\hline 0 & 165 & $26.52 \pm 5.40$ & & \\
\hline$<30$ & 88 & $26.28 \pm 5.07$ & 1.876 & 0.155 \\
\hline$\geq 30$ & 113 & $27.62 \pm 5.89$ & & \\
\hline \multicolumn{5}{|c|}{ Initial working time (years) } \\
\hline$<20$ & 144 & $26.69 \pm 5.44$ & 0.791 & 0.429 \\
\hline$\geq 20$ & 222 & $27.18 \pm 6.00$ & & \\
\hline \multicolumn{5}{|l|}{ Work years (years) } \\
\hline$<20$ & 170 & $23.02 \pm 5.12$ & 12.290 & $<0.001$ \\
\hline$\geq 20$ & 196 & $29.98 \pm 6.12$ & & \\
\hline \multicolumn{5}{|c|}{ Working age for occurrence } \\
\hline$<10$ & 130 & $27.33 \pm 5.85$ & 1.403 & 0.161 \\
\hline$\geq 10$ & 136 & $26.48 \pm 5.48$ & & \\
\hline
\end{tabular}

Table 3: Comparisons of the expression levels of Bcl-2, Caspase-3 and Caspase-8 in the exposed group

\begin{tabular}{ccccc}
\hline Group & Case group & Control group & $\chi^{2} / \boldsymbol{t}$ & $\boldsymbol{P}$ \\
\hline Bcl-2 & $0.291 \pm 0.044$ & $0.211 \pm 0.038$ & 17.850 & $<0.001$ \\
Caspase-3 & $0.338 \pm 0.050$ & $0.267 \pm 0.040$ & 14.140 & $<0.001$ \\
Caspase-8 & $0.237 \pm 0.041$ & $0.219 \pm 0.034$ & 3.137 & 0.002 \\
\hline
\end{tabular}

Note: these results were not influenced following the adjustment for cofounders such as age, smoking history and other baseline factors.
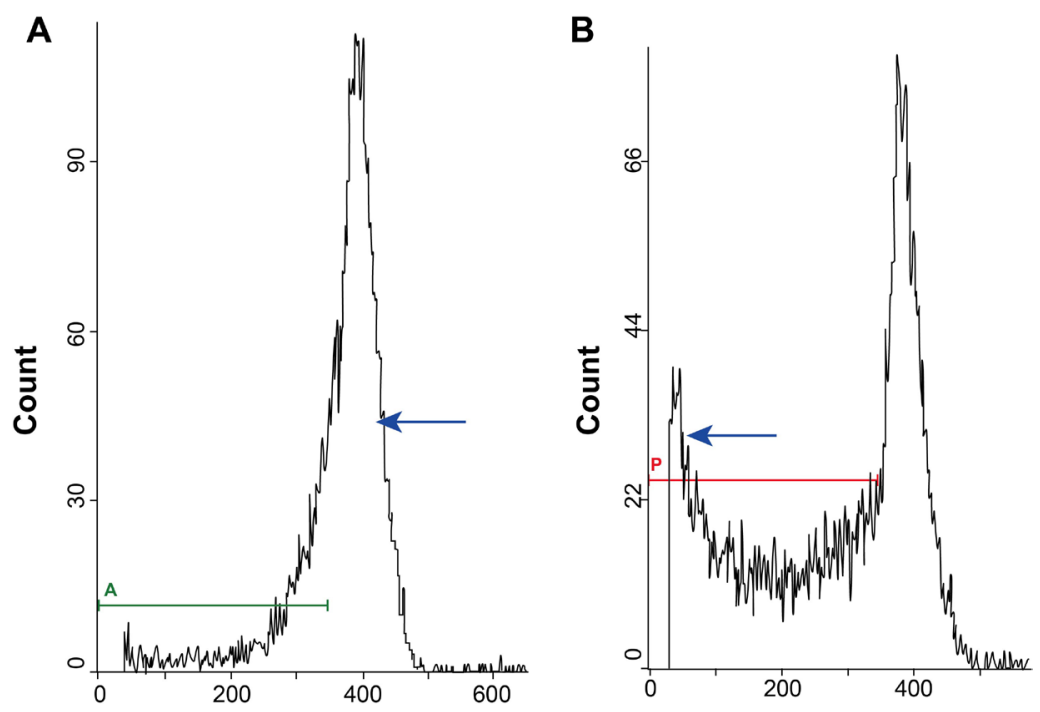

Figure 2: Flow cytometry analysis of apoptoticalveolar macrophages cells showing the sub-diploid (sub-G0/G1) peak. (A) FACS plots showing normal peaks forcontrol alveolar macrophages; (B) FACS plot showing sub-diploidpeak representing alveolar macrophages undergoing apoptosis. 
Table 4: Comparisons of the expression levels of Bcl-2, Caspase-3 and Caspase-8 among different subgroups based on age, smoking, initial working time, occupational time, and working age for occurrence in the exposed group

\begin{tabular}{lcccc}
\hline \multicolumn{1}{c}{ Group } & N & Bcl-2 & Caspase-3 & Caspase-8 \\
\hline Age & & & & \\
$\quad<40$ & 156 & $0.356 \pm 0.047$ & $0.354 \pm 0.047$ & $0.032 \pm 0.045$ \\
$\quad \geq 40$ & 210 & $0.310 \pm 0.035^{*}$ & $0.322 \pm 0.042^{*}$ & $0.038 \pm 0.043$ \\
$\quad$ Smoking (duration time, years) & & & & \\
$\quad 0$ & 165 & $0.345 \pm 0.054$ & $0.401 \pm 0.054$ & $0.376 \pm 0.050$ \\
$\quad<30$ & 88 & $0.336 \pm 0.048$ & $0.367 \pm 0.041^{*}$ & $0.382 \pm 0.056$ \\
$\quad 13$ & $0.342 \pm 0.043$ & $0.375 \pm 0.050^{*}$ & $0.367 \pm 0.048$ \\
$\quad$ Initial working time (years) & & & & \\
$\quad<20$ & 144 & $0.288 \pm 0.043$ & $0.376 \pm 0.055$ & $0.256 \pm 0.035$ \\
$\quad \geq 20$ & 222 & $0.231 \pm 0.034^{*}$ & $0.345 \pm 0.036^{*}$ & $0.218 \pm 0.040^{*}$ \\
$\quad$ Working years (years) & & & & \\
$\quad<20$ & 170 & $0.288 \pm 0.060$ & $0.377 \pm 0.062$ & $0.236 \pm 0.056$ \\
$\quad \geq 20$ & 196 & $0.243 \pm 0.051^{*}$ & $0.332 \pm 0.054^{*}$ & $0.228 \pm 0.047$ \\
Working age for occurrence & & & & \\
$\quad<10$ & 130 & $0.227 \pm 0.057$ & $0.376 \pm 0.067$ & $0.321 \pm 0.046$ \\
$\quad \geq 10$ & 136 & $0.234 \pm 0.048$ & $0.337 \pm 0.068^{*}$ & $0.327 \pm 0.050$ \\
\hline
\end{tabular}

Note: ${ }^{*} P<0.05$ when compared between two subgroups.

indicated that AM cells from CWP patients were prone to excessive apoptosis than that of the normal controls. Although mechanisms regulating CWP are not clear, $\mathrm{AM}$ apoptosis has been postulated to be responsible for the pathological development of pulmonary fibrosis [31]. Specifically, apoptosis of AM cells results in production of large amounts of inflammatory cytokines and fibrogenic factors thatpotentiallyplay an important role in the pathogenesis and development of CWP [32]. Apoptosisincludessignal transduction, sequential activation of apoptotic genes, execution of apoptosis and subsequent removal of apoptotic cells [33]. We demonstrated that

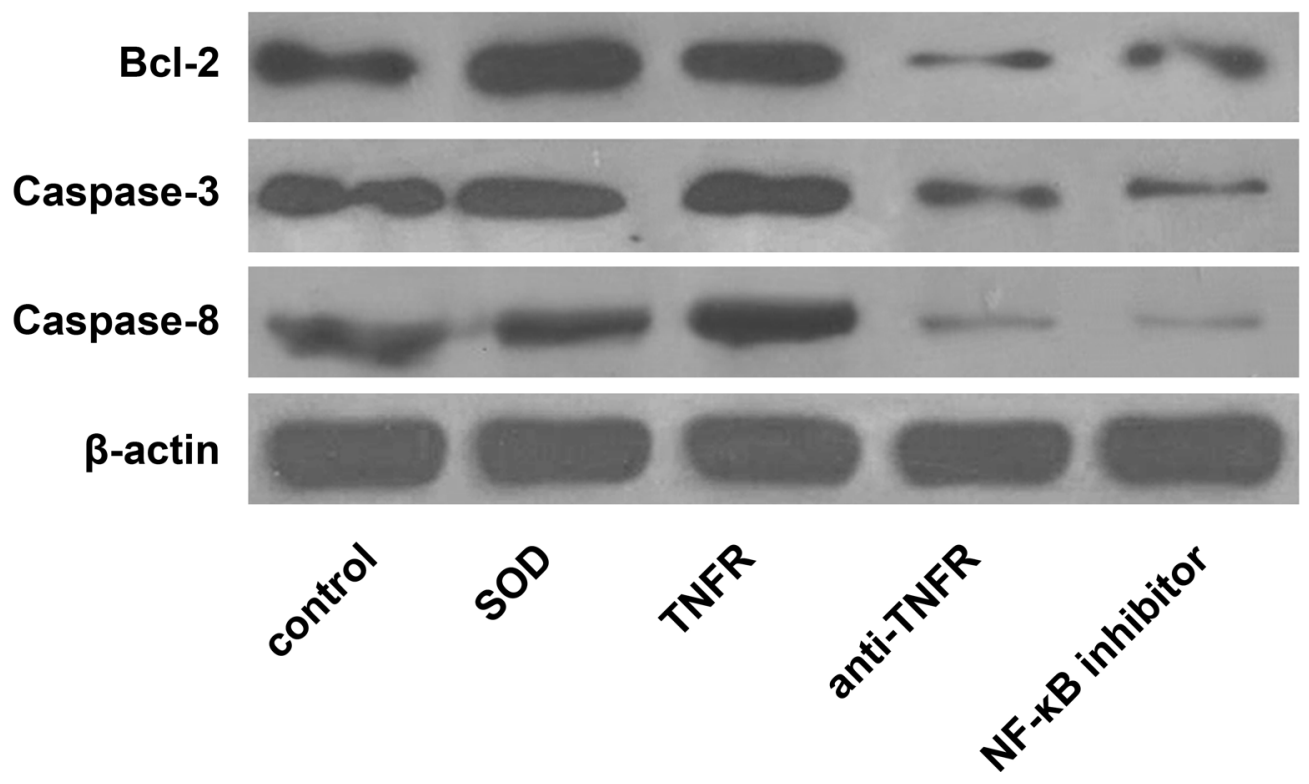

Figure 3: Western blot analyses of apoptosisregulatoryproteins among the 5 experimental groups of alveolar macrophages. The 5 experimental groups are as follows: A, control group; B, SOD group; C, TNFR group; D, anti-TNFR group; E, NF-kB inhibitor group. 
Table 5: Comparisons of the expression levels of Bcl-2, Caspase-3 and Caspase-8 among different subgroups based on the application of different intervention approaches

\begin{tabular}{lcccccc}
\hline Protein & Group & SOD treatment & Group & anti-TNFR treatment & Group & NF-kB inhibitor treatment \\
\hline Bcl-2 & & & & & & \\
& A & $0.291 \pm 0.056$ & A & $0.324 \pm 0.045$ & A & $0.350 \pm 0.044$ \\
& B & $0.147 \pm 0.034^{*}$ & C & $0.264 \pm 0.035^{*}$ & C & $0.265 \pm 0.040^{*}$ \\
& C & $0.245 \pm 0.034^{* *}$ & D & $0.160 \pm 0.033^{* *}$ & E & $0.165 \pm 0.031^{* *}$ \\
Caspase-3 & & & & & & \\
& A & $0.198 \pm 0.024$ & A & $0.231 \pm 0.050$ & A & $0.231 \pm 0.041$ \\
& B & $0.134 \pm 0.030^{*}$ & C & $0.224 \pm 0.042$ & C & $0.221 \pm 0.038$ \\
& C & $0.200 \pm 0.037^{* *}$ & D & $0.154 \pm 0.032^{* *}$ & E & $0.143 \pm 0.030^{* *}$ \\
Caspase-8 & & & & & & \\
& A & $0.234 \pm 0.050$ & A & $0.238 \pm 0.056$ & A & $0.242 \pm 0.042$ \\
& B & $0.153 \pm 0.034^{*}$ & $\mathrm{C}$ & $0.230 \pm 0.043$ & $\mathrm{C}$ & $0.195 \pm 0.034^{*}$ \\
& $\mathrm{C}$ & $0.213 \pm 0.042^{* *}$ & $\mathrm{D}$ & $0.182 \pm 0.040^{* *}$ & $\mathrm{E}$ & $0.162 \pm 0.027^{* *}$ \\
\hline
\end{tabular}

Note: A, control group; B, SOD group; C, TNFR group; D, anti-TNFR group; E, NF-kB inhibitor group. ${ }^{*} P<0.05$ when compared with group $\mathrm{A} ;{ }^{* *} \mathrm{P}<0.05$ when compared with group $\mathrm{B}$ or group $\mathrm{C}$.

the AM cells from CWP patients underwent excessive apoptosis than controls as visualized by the sub-diploid (sub-G0/G1) apoptosis peak in flow cytometry assays.

In vivo and in vitro studies have shown that $\mathrm{AM}$ plays an important role in CWP. AM arethe main target cells exposed to dust andincreased AM numbers are observed in CWP patients that correspondto excess amount of dust in the lungs [34]. Length of exposure to dust and the onset age are critical determinant factors in the incidence of CWP. Our study demonstrated that the apoptosis index of AM increased with the increase degree of CWP. Further, our data showed that increased length of exposure to dust in the CWP patients resulted in higher expression levels of Bcl-2, Caspase-3 and Caspase-8. Hence, our data suggested that longer coal dust exposure timeresulted in higher levels of AM apoptosis, which in turn increased incidence of CWP.

More importantly, we observed the relationship between TNFR/TNF- $\alpha$ signal transduction pathway on AM apoptosis [35] and the higher expression of critical apoptotic proteins in CWP patients, namelyBcl-2, Caspase- 3 and Caspase- 8 . Our data also showed that blocking TNFR/TNF- $\alpha$ mediated AM apoptosis by antiTNFR antibody resulted in decreased apoptosis and expression of Bcl-2, Caspase-3 and Caspase-8, thereby suggesting that TNFR/TNF- $\alpha$ signal transduction pathway was a key player in AM apoptosis and CWP.

Caspases area group of cysteine-aspartate proteases that are activated in a step wise manner upon apoptotic signaling [36]. The apoptotic signaling pathways activateinitiatorCaspasessuch asCaspases-8, -9 , and -10 , which then cleave and activate theeffectorCaspases such as Caspases- $3,-6$, and -7 that cleave critical proteins required for cellular homeostasis and function resulting eventually in deathof target cells [37-39]. Caspase-8 is an initiator caspase found upstream of the Caspase cascade, whereasCaspase- 3 is an important effector caspasethat is critical for accomplishing cellular apoptosis [40]. We demonstrated that treating AM cells with anti-TNFRantibody that blocks TNFR/TNFasignaling apoptotic pathway resulted in decreased apoptosis of AM cells and diminished expression of Bcl-2, Caspase-3 and Caspase-8. This suggested that inhibitors ofTNFR/ TNF-asignaling may potentially benefitCWP patients therapeutically as it would enhance survival of AM cells and thereby alleviate CWP

In conclusion, our study demonstrates that constant and excessive exposure to coal dust results in excessive apoptosis of AM due to stimulation of the TNFR/TNFaapoptotic signaling pathway that leads to enhanced expression of apoptosis related proteins like Bcl-2, Caspase-3 and Caspase-8. Our study also demonstrated that inhibiting TNFR/TNF-asignaling pathway byeither anti-TNFR antibody or inhibitors like SOD or NFkB inhibitors results in reduced AM apoptosis suggesting a potential therapeutic target to alleviate CWP.

\section{MATERIALS AND METHODS}

\section{Ethical statement}

The study was approved by the Ethics committee ofTangshan Gongren Hospital affiliated to North China University of Science and Technology. All subjects or their legal guardians provided written informed consents. Study protocols followed the ethical principles for medical research involving human subjects according to the Helsinki Declaration [41]. 


\section{Study subjects}

For this study, 366 coal mine workersfrom Kailuan Colliery, China (exposed group)that received treatment in Tangshan Gongren Hospital affiliated to North China University of Science and Technologywere recruitedas the research subjects. They were diagnosedfor pneumoconiosis in accordance with the specific standards of National Diagnostic Criteria of Pneumoconiosis [42] and subdivided into CWP stage I $(n=180)$ and CWP stage II $(n=186)$ groups. Subjectswere enrolled if (1) they were Han males; (2) they were exposed todustover 1 year; (3) they hadcomplete physical examination during the past two years; and (4) had complete records ofoccupational history or could be supplemented via checking working files. Patients with related lung diseases such as pneumonia, lung cancer, and active pulmonary tuberculosis were all excluded from this study. Also, patients diagnosed with pneumoconiosis combined with pulmonary complications, severe heart\&lung diseases and infectious diseases were also excluded. In addition, 120 coal mine workers without previous history of anypulmonary diseases were enrolled in the present study as the control group.

Information regarding baseline characteristics was collected by face to facequestionnaires to avoid contradictions or difficulties in obtaining complete information or through telephone interviews with retired workers. The data included (1) demographic characteristicslike age, date of birth, gender, weight and height, smoking status, initial exposure time, occupational history, current occupation, and retirement age; (2) dust exposure history, which included initial exposure time, average exposure time, and age of dust removal; (3) pulmonary disease history that included time of initial diagnosis, grade, complications and onset time of complications. Most of the information was obtained from the medical records of the patients from Tangshan Gongren Hospital affiliated to North China University of Science and Technology. Further information wasobtained from occupational health examination records and face to face inquiries. Information regarding dust exposure, diagnostic information of pneumoconiosis and other relevant complications wascollected from the hospital recording files atTangshan Gongren Hospital affiliated to North China University of Science and Technology.

\section{Experimental methods}

\section{Alveolar macrophage cell cultureand grouping}

The subjects enrolled for this study underwent large capacity double lung simultaneous irrigation operation under general anesthesia at the Pneumoconiosis rehabilitation center of National Coal Mine Safety Supervision Bureau. After an appropriate amount of bronchoalveolar lavage fluid washarvested, it wasfilteredthroughthree layers of sterile gauze, followed by centrifugation. The supernatant was discarded and the cell pelletswere subsequently washedthrice in PBSand centrifuged to obtain the AM cell suspension that was diluted in appropriate amounts 10\% DMEM medium and cell counts obtained.

The AM cell suspension $\left(5 \times 10^{6}\right)$ was seeded in 6-well culture plates in $2 \mathrm{ml}$ DMEM mediumcontaining $10 \%$ heat inactivated FBS and placed in a culture box with $84 \%$ humidity, $5 \% \mathrm{CO}_{2}$ and $37^{\circ} \mathrm{C}$ for $2 \mathrm{~h}$. The non-adherent cells were discarded and fresh DMEM medium was added to the adherent cells that represented the purified AM.

After purification, the AM cells were divided into five experimental groups as follows: (1) control group without any treatment; (2) SOD group that received200U/ $\mathrm{ml} \mathrm{SOD;} \mathrm{(3)} \mathrm{TNFR} \mathrm{group} \mathrm{that} \mathrm{received} 50 \mathrm{ng} / \mathrm{ml}$ antiTNF- $\alpha$ antibody; (4) anti-TNFR group that received 50ng/ $\mathrm{ml}$ anti-TNF- $\alpha$ antibody with200ng/ml anti-TNFR; and (5) NFkB inhibitor group.

Furthermore, as for AM culture and harvest, after reagents were added, the cells were incubatedfor $24 \mathrm{~h}$ ( $84 \%$ humidity, $5 \% \mathrm{CO}_{2}$ volume fraction in $37^{\circ} \mathrm{C}$ ). The 5 groups of cells were grown for $24 \mathrm{~h}$ at $37^{\circ} \mathrm{C}$ and $5 \%$ $\mathrm{CO}_{2}$ following which the supernatant was discarded and the adherent cells were trypsinized with $0.25 \%$ trypsin for $1 \mathrm{~min}$. Then, the cells in each group were collected, and washed thrice with PBS followedby centrifugation for $10 \mathrm{mins}$ at $1000 \mathrm{rpm}$ and the pelleted cells were resuspended and counted. The collected cells were stored for analyzingapoptosis. A portion of the cells were stained with hematoxylin\&eosinand observed under the microscope to assess morphological changes associated with apoptosis.

\section{Flow cytometry assay for AM apoptosis detection}

The AM cells in the 5 experimental groups were fixed with cold $70 \%$ ethanol and analyzed in a flow cytometer, among which the reaction tube was added with $200 \mu \mathrm{l}$ binding buffer and $5 \mu \mathrm{l}$ propidium iodide. The percent cells in the sub-G0/G1 peak represented cells undergoing apoptosis. The sub-G0/G1 was identified from the FSC-H versus SSC-H plots.

\section{Western blot analysis of apoptotic signaling proteins}

The AM cells from the 5 experimental groups were incubated in protein lysis buffer (BeyotimeInstitute of Biotechnology) for $30 \mathrm{~min}$ at $4^{\circ} \mathrm{C}$ with intermittent vigorous mixing. After centrifugation at $1000 \mathrm{rpm}$ for $15 \mathrm{~min}$ at $4{ }^{\circ} \mathrm{C}$, the supernatant was stored at $-80^{\circ} \mathrm{C}$. The protein amount in the lysate was quantified using the Bradford assay kit (BioRad, Hercules, CA, USA). Then, the protein samples were separated on $10 \%$ SDS PAGE and transferred onto PVDF membrane $(1.5 \mathrm{~h})$. The initial voltage was $60 \mathrm{~V}$, and elevated at $120 \mathrm{~V}$ when the front edge of the bromophenol blue into the seperation gel. the After blocking, the membrane was incubated with primary 
antibody (Anti-human Bcl-2, Caspase-3 and Caspase-8 and anti-human $\beta$-actin, dilution ratio of $1: 2000$, provided by the Santa cruz co., Ltd, CA, USA) for 1hfollowed by incubation with 1:2000dilutedgoat anti-rabbit secondary antibody for $45 \mathrm{~min}$ at $37^{\circ} \mathrm{C}$. The blot was developed with ECL method (ECL reaction mixture, Santa cruz co., Ltd, CA, USA) and the protein bands were quantified by the image analysis software IPP 6.0.

\section{Statistical analysis}

SPSS17.0 software was used for statistical analysis. Continuous variables were presented as mean \pm S.D; categorical variables were presented as frequencies and percentages. Comparisons between continuous variables were analyzedby $t$ test and $F$ test, whereas Wilcoxon rank-sum test was used for comparisons of non-randomlydistributed continuous variables. The chi-square test was used for categorical variables. Correlations were analyzed by Pearson correlation analysis. A $P$ value of $<0.05$ was considered statistically significant.

\section{ACKNOWLEDGMENTS}

We would like to thank our researchers for their hard work and colleagues for their valuable advice.

\section{CONFLICTS OF INTEREST}

All authors in our study have no conflicts of interest.

\section{REFERENCES}

1. Xia Y, Liu J, Shi T, Xiang H, Bi Y. Prevalence of pneumoconiosis in Hubei, China from 2008 to 2013. Int J Environ Res Public Health. 2014; 11:8612-21.

2. Baur X, Heger M, Köhler D, Kranig A, Letzel S, SchultzeWerninghaus G, Tannapfel A, Teschler H, Voshaar T, Bohle MR, Erlinghagen N, Hering KG, Hofmann-Preiss K, et al, and Deutsche Gesellschaft für Arbeitsmedizin und Umweltmedizin. [Diagnostics and expert opinion in the occupational disease No. 4101 silicosis (including coal worker's pneumoconiosis). Guideline (S2; AWMF) of the Deutsche Gesellschaft für Pneumologie und Beatmungsmedizin and the Deutsche Gesellschaft für Arbeitsmedizin und Umweltmedizin]. [Article in German]. Pneumologie. 2008; 62:659-84.

3. Sens PM, Almeida CI, Valle LO, Costa LH, Angeli ML. Tuberculosis of the ear, a professional disease? Braz J Otorhinolaryngol. 2008; 74:621-7.

4. Kamal A, Malik RN, Martellini T, Cincinelli A. Cancer risk evaluation of brick kiln workers exposed to dust bound PAHs in Punjab province (Pakistan). Sci Total Environ. 2014; 493:562-70.

5. Torres Rey CH, Ibanez Pinilla M, Briceno Ayala L, Checa Guerrero DM, Morgan Torres L, Groot de Restrepo H,
Varona Uribe M. Underground Coal Mining: Relationship between Coal Dust Levels and Pneumoconiosis, in Two Regions of Colombia, 2014. Biomed Res Int. 2015; 2015:647878.

6. Hedmer M, Karlsson JE, Andersson U, Jacobsson H, Nielsen J, Tinnerberg H. Exposure to respirable dust and manganese and prevalence of airways symptoms, among Swedish mild steel welders in the manufacturing industry. Int Arch Occup Environ Health. 2014; 87:623-34.

7. Laney AS, Green F, Petsonk E. Pathologic Characteristics Of Coal Workers' Pneumoconiosis By Primary Radiographic Small Opacity Shape. American Journal of Respiratory \& Critical Care Medicine. 2013.

8. Mo J, Wang L, Au W, Su M. Prevalence of coal workers' pneumoconiosis in China: a systematic analysis of 20012011 studies. Int J Hyg Environ Health. 2014; 217:46-51.

9. Wang M, Wang S, Song Z, Ji X, Zhang Z, Zhou J, Ni C. Associations of IL-4, IL-4R, and IL-13 gene polymorphisms in coal workers' pneumoconiosis in China: a case-control study. PLoS One. 2011; 6:e22624.

10. Miller BG, MacCalman L. Cause-specific mortality in British coal workers and exposure to respirable dust and quartz. Occup Environ Med. 2010; 67:270-6.

11. Shen F, Liu H, Yuan J, Han B, Cui K, Ding Y, Fan X, Cao H, Yao S, Suo X, Sun Z, Yun X, Hua Z, et al. CostEffectiveness of Coal Workers' Pneumoconiosis Prevention Based on Its Predicted Incidence within the Datong Coal Mine Group in China. PLoS One. 2015; 10:e0130958.

12. Najmuddin A, Cohen RA, Petsonk EL, Young B, MacNeill S, Tramma S, Regier M, Abraham JL, Churg A, Green F. Lung pathology in coal workers with rapidly progressive pneumoconiosis emphasizes importance of silica and silicates in addition to carbon. American Journal of Respiratory \& Critical Care Medicine. 2014.

13. Hoshino A, Hanada S, Yamada H, Mii S, Takahashi M, Mitarai S, Yamamoto K, Manome Y. Mycobacterium tuberculosis escapes from the phagosomes of infected human osteoclasts reprograms osteoclast development via dysregulation of cytokines and chemokines. Pathog Dis. 2014; 70:28-39.

14. Radogna F, Dicato M, Diederich M. Cancer-type-specific crosstalk between autophagy, necroptosis and apoptosis as a pharmacological target. Biochem Pharmacol. 2015; 94:1-11.

15. Schweikl H, Petzel C, Bolay C, Hiller KA, Buchalla W, Krifka S. 2-Hydroxyethyl methacrylate-induced apoptosis through the ATM- and p53-dependent intrinsic mitochondrial pathway. Biomaterials. 2014; 35:2890-904.

16. Fu Z, Zou F, Deng H, Zhou H, Liu L. Estrogen protects SGC7901 cells from endoplasmic reticulum stress-induced apoptosis by the Akt pathway. Oncol Lett. 2014; 7:560-4.

17. Lim SC, Parajuli KR, Han SI. The alkyllysophospholipid edelfosine enhances TRAIL-mediated apoptosis in gastric cancer cells through death receptor 5 and the mitochondrial pathway. Tumour Biol. 2016; 37:6205-16. 
18. Teocchi MA, D'Souza-Li L. Apoptosis through Death Receptors in Temporal Lobe Epilepsy-Associated Hippocampal Sclerosis. Mediators Inflamm. 2016; 2016:8290562.

19. Wang L, Liu S, Zhao Y, Liu D, Liu Y, Chen C, Karray S, Shi S, Jin Y. Osteoblast-induced osteoclast apoptosis by fas ligand/FAS pathway is required for maintenance of bone mass. Cell Death Differ. 2015; 22:1654-64.

20. Qu J, Zhao M, Teng Y, Zhang Y, Hou K, Jiang Y, Yang X, Shang H, Qu X, Liu Y. Interferon-alpha sensitizes human gastric cancer cells to TRAIL-induced apoptosis via activation of the c-CBL-dependent MAPK/ERK pathway. Cancer Biol Ther. 2011; 12:494-502.

21. Song HY, Deng XH, Yuan GY, Hou XF, Zhu ZD, Zhou L, Ren MX. Expression of bcl-2 and p53 in induction of esophageal cancer cell apoptosis by ECRG2 in combination with cisplatin. Asian Pac J Cancer Prev. 2014; 15:1397-401.

22. Yao SQ, Zhang XY, Chen ZY. [Regulation role of superoxide dismutase coenzyme on Fas/FasL signal transduction and apoptosis in alveolar macrophages of pneumoconiosis patients]. [Article in Chinese]. Zhonghua Lao Dong Wei Sheng Zhi Ye Bing Za Zhi. 2008; 26:271-5.

23. Shen F, Yuan J, Sun Z, Hua Z, Qin T, Yao S, Fan X, Chen W, Liu H, Chen J. Risk identification and prediction of coal workers' pneumoconiosis in Kailuan Colliery Group in China: a historical cohort study. PLoS One. 2013; 8:e82181.

24. Wang M, Jin Y, Chen S, Yao S, Zhu L, Duan J, Yuan J. [The study of autophagy in alveolar macrophages of patients with coal workers' pneumoconiosis]. [Article in Chinese]. Zhonghua Lao Dong Wei Sheng Zhi Ye Bing Za Zhi. 2015; 33:41-4.

25. Zhang CM, Bai YP, Yan-Qin YU, Chen ZY, Zhang ZH. Significance of apoptosis-related proteins in the occurrence and progression of coal workers' pneumoconiosis. China Occupational Medicine. 2011.

26. Campagnolo L, Costanza G, Francesconi A, Arcuri G, Moscatelli I, Orlandi A. Sortilin expression is essential for pro-nerve growth factor-induced apoptosis of rat vascular smooth muscle cells. PLoS One. 2014; 9:e84969.

27. Ge Y, Yan D, Deng H, Chen W, An G. Novel Molecular Regulators of Tumor Necrosis Factor-Related ApoptosisInducing Ligand (TRAIL)-Induced Apoptosis in NSCLC Cells. Clin Lab. 2015; 61:1855-63.

28. Gawaz M,Vogel S. Platelets in tissue repair: control of apoptosis and interactions with regenerative cells. Blood. $2013 ; 122: 2550-4$.

29. Neumann S, Hasenauer J, Pollak N, Scheurich P. Dominant negative effects of tumor necrosis factor (TNF)-related apoptosis-inducing ligand (TRAIL) receptor 4 on TRAIL receptor 1 signaling by formation of heteromeric complexes. J Biol Chem. 2014; 289:16576-87.

30. Soini Y, Eerola AK, Lehto VP, Pääkkö P. Increased numbers of alveolar macrophages with apoptotic bodies predict lung carcinoma. Apoptosis. 1998; 261-6.
31. Ueno M, Maeno T, Nomura M, Aoyagi-Ikeda K, Matsui H, Hara K, Tanaka T, Iso T, Suga T, Kurabayashi M. Hypoxiainducible factor-1alpha mediates TGF-beta-induced PAI-1 production in alveolar macrophages in pulmonary fibrosis. Am J Physiol Lung Cell Mol Physiol. 2011; 300:L740-52.

32. van Berlo D, Wilhelmi V, Boots AW, Hullmann M, Kuhlbusch TA, Bast A, Schins RP, Albrecht C. Apoptotic, inflammatory, and fibrogenic effects of two different types of multi-walled carbon nanotubes in mouse lung. Arch Toxicol. 2014; 88:1725-37.

33. Xu X, Wen H, Hu Y, Yu H, Zhang Y, Chen C, Pan X. STAT1-caspase 3 pathway in the apoptotic process associated with steroid-induced necrosis of the femoral head. J Mol Histol. 2014; 45:473-85.

34. Davies R, Erdogdu G. Secretion of fibronectin by mineral dust-derived alveolar macrophages and activated peritoneal macrophages. Exp Lung Res. 1989; 15:285-97.

35. Tsou HK, Chen HT, Chang CH, Yang WY, Tang CH. Apoptosis signal-regulating kinase 1 is mediated in TNF-alpha-induced CCL2 expression in human synovial fibroblasts. J Cell Biochem. 2012; 113:3509-19.

36. Wu H, Che X, Zheng Q, Wu A, Pan K, Shao A, Wu Q, Zhang J, Hong Y. Caspases: a molecular switch node in the crosstalk between autophagy and apoptosis. Int J Biol Sci. 2014; 10:1072-83.

37. Samarghandian S, Nezhad MA, Mohammadi G. Role of caspases, Bax and Bcl-2 in chrysin-induced apoptosis in the A549 human lung adenocarcinoma epithelial cells. Anticancer Agents Med Chem. 2014; 14:901-9.

38. Kim WH, Song HO, Choi HJ, Bang HI, Choi DY, Park H. Ethyl gallate induces apoptosis of HL-60 cells by promoting the expression of caspases- $8,-9,-3$, apoptosis-inducing factor and endonuclease G. Int J Mol Sci. 2012; 13:11912-22.

39. Inserte J, Cardona M, Poncelas-Nozal M, Hernando V, Vilardosa U, Aluja D, Parra VM, Sanchis D, GarciaDorado D. Studies on the role of apoptosis after transient myocardial ischemia: genetic deletion of the executioner caspases-3 and -7 does not limit infarct size and ventricular remodeling. Basic Res Cardiol. 2016; 111:18.

40. Mitupatum T, Aree K, Kittisenachai S, Roytrakul S, Puthong S, Kangsadalampai S, Rojpibulstit P. Hep88 mAb-mediated paraptosis-like apoptosis in HepG2 cells via downstream upregulation and activation of caspase- 3 , caspase- 8 and caspase-9. Asian Pac J Cancer Prev. 2015; 16:1771-9.

41. General Assembly of the World Medical Association. World Medical Association Declaration of Helsinki: ethical principles for medical research involving human subjects. J Am Coll Dent. 2014; 81:14-8.

42. Paolucci V, Sartorelli P. Diagnostic Criteria Of Pneumoconiosis. 2013; 36. 